\title{
Accreditation on Biomedical and Health Informatics in Europe: Guidelines and Procedures
}

\author{
Emmanouil ZOULIAS ${ }^{\mathrm{a}}$ and John MANTAS ${ }^{\mathrm{a}, 1}$ \\ ${ }^{a}$ Health Informatics Laboratory, Faculty of Nursing, National and Kapodistrian \\ University of Athens, Athens, Greece
}

\begin{abstract}
Accreditation is the evaluation and monitoring process assuring that educational programs and institutions meet academic standards and operational integrity and quality. The number of programs in the field of Biomedical and Health Informatics is rapidly increasing. In this paper we briefly introduce the accreditation procedure that has been established by Accreditation Committee (AC2) of European Federation of Medical Informatics according to international standards.
\end{abstract}

Keywords. Biomedical and Health Informatics, accreditation, education

\section{Introduction}

Accreditation is a diligent evaluation and monitoring peer review process assuring that educational programs and institutions meet academic standards and operational integrity and quality [1]. There is a great number of European Universities and Institutions implementing and having established programs (undergraduate and postgraduate) in the field of Biomedical and Health Informatics [2]. A mechanism already applied by EFMI to accredit those programs, since EFMI is the European scientific body of Biomedical and Health Informatics, where all national associations have joined in EFMI. This accreditation provides European added value to the programs, be supportive of crossnational mobility and be complimentary to the required national accreditations processes [3]. The number of programs in the field of Health Informatics increased in Europe. On the other hand, a small number of Universities/Institutions with an accredited program in the field of Health Informatics reveals that accreditation activities have low effect in Europe.

EFMI is represented by the AC2 Committee which establishes an Accreditation and Certification process across. The aim of EFMI AC2 initiative is the promotion and provision awareness of the educational initiative to the wider biomedical and health informatics community in Europe.

${ }^{1}$ Corresponding Author, John Mantas, Health Informatics Laboratory, Faculty of Nursing, National and Kapodistrian University of Athens, Athens, Greece; E-mail: jmantas@nurs.uoa.gr. 


\section{Methods}

The EFMI AC2 Accreditation assessment do not intend to replace or overcome any National or International accreditation or law. The accreditation process is robust and smooth succession of well-established steps and has already applied throughout Europe. The aim of EFMI AC2 Accreditation is to act as a complimentary judgement assisting and supporting to reach high quality academical educational programs in the field of Biomedical and Health Informatics.

The assessment procedure for successful accreditation examines five criteria. The criteria are based on the Dublin descriptors. Dublin Descriptors are uniform requirements for higher education under the Bologna Process acting as a system of qualifications frameworks for evaluating students for bachelor's, master's, doctoral degrees [4].

The EFMI AC2 Accreditation criteria are the following:

1. Needs and relevance

2. Intended learning outcomes

3. Academic/Teaching-learning environment

4. Organization and implementation

5. Internal quality assurance and development

The results of the assessment for each criterion are either satisfactory or unsatisfactory. In case that all five (5) criteria are satisfactory, according to the site-visit panel, the result of accreditation will be positive for the Universities/Institutions. The final decision of EFMI AC2 Committee is based on the evaluation report of site-visit panel. The positive decision of EFMI AC2 Committee gives the grant of EFMI Accreditation to the programme for three years. A re-accreditation process is required at the end of this period [5]-[8].

In case that only one (1) out of five (5) criteria measured as unsatisfactory then the programme receives a partial EFMI Accreditation for one year, until the program will reach this criterion. The application for accreditation will be dropped if more than two (2) criteria are judged as unsatisfactory. At least one year period of time is needed after a dropped application for a new judgement iteration.

\section{Results}

The AC2 by EFMI had successfully examined a wide variety of specializations including Biomedical Informatics, Health Informatics, Medical Informatics, Medical Technology, Bioinformatics, Biomedical Engineering, at undergraduate / postgraduate / doctoral / postdoctoral Studies. The information provided by an on-line catalogue ${ }^{2}$, providing information about European programmes and courses of different Universities/Colleges/Institutions with $1000 \mathrm{BMHI}$ programs and related specializations.

\footnotetext{
${ }^{2}$ http://efmi-ac2.bmhi-edu.org/
} 


\section{Conclusion}

The first results by the EFMI AC2 procedure has already been initiated, and a number of programs have already been accredited. The first accreditation of Austrian UMIT received an award during MIE2021 in Athens. An accreditation process in BMHI needs to be based on updated educational recommendations by international organisations [9][12] in the field that will encompass all health care professions needs and requirements in clinical, nursing, and public health institutions, universities and health organisations.

\section{References}

[1] Mantas J. Accreditation and Certification in Health Informatics: Principles and Procedures. In ICIMTH 2017 Jan 1 (pp. 272-275).

[2] Kolokathi A, Hasman A, Chronaki C, Madsen I, Moen A, Randell R, Mantas J. Education in biomedical and health informatics: A European perspective. Studies in health technology and informatics. 2019;264:1951-2.

[3] Mantas J. Accreditation and Certification in Europe on Biomedical and Health Informatics as provided by EFMI. Bilten Hrvatskog društva za medicinsku informatiku (Online). 2021 Jul 11;27(2):1-8.

[4] Masaev SN, Dorrer GA, Vingert VV, Yakimova EA, Klochkov SV. Dublin Descriptors. In Journal of Physics: Conference Series 2020 Nov 1 (Vol. 1691, No. 1, p. 012021). IOP Publishing.

[5] Mantas J. The Accreditation Procedure Ensures Quality of Education in Biomedical and Health Informatics. Stud Health Technol Inform. 2020 Jun 26;272:484-486. doi: 10.3233/SHTI200601. PMID: 32604708 .

[6] Mantas J. The European Educational Programs in Biomedical and Health Informatics. Stud Health Technol Inform. 2020 Jun 26;272:482-483. doi:10.3233/SHTI200600. PMID: 32604707.

[7] Mantas J. Accreditation and Certification in Health Informatics: Principles and Procedures. Stud Health Technol Inform. 2017;238:272-275. PMID: 28679942.

[8] Jaspers MW, Mantas J, Borycki E, Hasman A. IMIA Accreditation of Biomedical and Health Informatics Education: Current State and Future Directions. Yearb Med Inform. 2017 Aug;26(1):252-256. doi: 10.15265/IY-2017-011. Epub 2017 Sep 11. PMID: 28480478; PMCID: PMC6239229.

[9] Mantas J, Hasman A. IMIA Educational Recommendations and Nursing Informatics.Stud Health Technol Inform. 2017;232:20-30. PMID: 28106578.

[10] Hasman A, Mantas J. IMIA Accreditation of Health Informatics Programs. Healthc Inform Res. 2013 Sep;19(3):154-61. doi: 10.4258/hir.2013.19.3.154. Epub 2013 Sep 30. PMID: 24175114; PMCID: PMC3810522.

[11] Mantas J, Hasman A, Shortliffe EH. Assessment of the IMIA educational accreditation process. Stud Health Technol Inform. 2013;192:702-6. PMID:23920647.

[12] Mantas J, Ammenwerth E, Demiris G, Hasman A, Haux R, Hersh W, Hovenga E, Lun KC, Marin H, Martin-Sanchez F, Wright G; IMIA Recommendations on Education Task Force. Recommendations of the International Medical Informatics Association (IMIA) on Education in Biomedical and Health Informatics. First Revision. Methods Inf Med. 2010 Jan 7;49(2):105-120. doi: 10.3414/ME5119. Epub ahead of print. PMID: 20054502. 